\begin{tabular}{c} 
International Journal of Biological Research, 3(1) (2015) $5-8$ \\
International Journal of Biological Research \\
SPC \\
Journal home page: $\begin{array}{c}\text { www.sciencepubco.com/index.php/IJBR } \\
\text { doi: } 10.14419 / i j b r . v 3 i 1.3737 \\
\text { Research Paper }\end{array}$ \\
\hline
\end{tabular}

\title{
Taxonomic significance of morphology and palynology of two species of Dracaena found in south eastern Nigeria
}

\author{
Chinyere V. Ilodibia ${ }^{1}$, C. U. Okeke ${ }^{1}$, Maureen U. Chukwuma ${ }^{2}$, Nneka F. Okeke ${ }^{1}$, \\ Ebele E. Akachukwu ${ }^{2}$, Bibian O. Aziagba ${ }^{1}$ \\ ${ }^{1}$ Department of Botany, Nnamdi Azikiwe University, P. M. B. 5025 Awka, Anambra State, Nigeria \\ ${ }^{2}$ Department of Biology, Nwafor Orizu College of Education Nsugbe, Anambra State, Nigeria \\ *Corresponding author E-mail: chinyereokafor206@yahoo.com
}

\begin{abstract}
Morphology and Palynology were carried out on Dracaena mannii Bak and Dracaena arborea Link various parts. T test was used for the analyses. Morphologically, the leaves of $D$. arborea are longer and wider than those of $D$. mannii, and the length of the internode of $D$. arborea is more than those of the D. mannii. Both species are trees and have the same inflorescence, floral, fruit and seed Morphology. Palynologically, the pollen grains of the two species are monocolpate with scabrate surfaces. The colpus in $D$. mannii is longer than that of $D$. arborea. The result also showed that there was no significant difference in the sizes of the pollen grains, the pollen form indices as well as length and diameter of the colpi of both $D$. arborea and D. mannii. The overall analyses showed no significant statistical difference in the morpology and palynology of the two Dracaena species. The implication is that the two species are closely related and this justified their placement under the same genus Draceana while the slight differences between them suggest the reason for their separation into different species.
\end{abstract}

Keywords: Dracaena Arborea; Dracaena Mannii; Dracaena Species; Morphology and Palynology.

\section{Introduction}

The genus Dracaena L. belongs to family Agavaceae. The genus Dracaena consists of about $50-80$ species native primarily to the old world tropics (Judd et al, 1998). According to Waterhouse (1987), Venter (1996), Dracaena consists of about 40 species, and to Huxley (1992), it consists of 50 species. Sharma (1993) and Dutta (2003) described it as a genus of about 150 species. The genus was first described by Linnaeus in 1767. Some species of Dracaena include Dracaena fragrans, D.surculosa, D. draco, D. marginata, D. arborea, D. goldiana, D.sanderina, D. deremensis, D. reflexa, D. mannii etc. Dracaenas are either shrubs or trees and are divided into two broad groups based on their growth habitstree Dracaenas and shrubby Dracaenas. Tree Dracaenas include Dracaena americana (Central American dragon tree), D. draco (Canary Islands draco tree), D. marginata, Dracaena mannii etc. while shrubby Dracaenas include D. aletriformis, D. bicolor, D. cincta, D. concinna, etc.(Waterhouse, 1987). Dracaenas are used as ornamentals, medicinal plants, in photo engraving, in research, as hedge plants, colourants, etc. In Europe and Canada, they are cultivated and sold as ornamentals, (Huxley, 1992). Dracaena arborea Link. and Dracaena mannii Bak. which are commonly found in south eastern Nigeria are the points of interest in this research. A system of classification of biological organisms which best reflects the totality of their similarities and differences is termed taxonomy, (Gill, 1988). To classify plants, taxonomists make use of morphology, phylogeny, physiology, phytochemistry, anatomy, cytology, palynology etc. as taxonomic lines of evidence to determine their similarities and differences in order to group them into various taxa. Dracaena mannii and Draceana arborea are grouped into the genus Draceana based on their similarities and into different species based on differences. According to Radford, (1986), the morphological data of plants are easily observable and obtainable, and are "thus used most frequently in taxonomic studies". The evidence from external morphology provides the "basic language for plant characterization, identification, classification and relationships" (Radford, 1986). Morphological features of plants are those external diagnostic features of plants (Philipson, 1971). These morphological features of plants according to Sharma (1993) include: vegetative characters, phonological characters, floral characters, seeds and fruits morphology etc. Palynology is the "study of pollen and spores" (Judd et al, 1999 and Sharma, 1993). Palynological characters have been used in solving several taxonomic problems, including the repositioning of several disputed taxa, and interpretation of problems relating to the origin and evolution of different groups. Determination of these differences and similarities with regards to morphology and palynology of the two species based on the outcome of the study were the objectives of this research.

\section{Materials and methods}

\subsection{Sources of materials}

Leaves, stems, roots, flowers, seeds and fruits of Dracaena species were collected from Nsukka town $\left(\mathrm{N} 06^{0} .86 .43 .5\right.$ and $\left.\mathrm{E} 07^{0} .42 .56 .0\right)$ in Nsukka, Nsukka Local Government Area Enugu State, Nigeria.

The Dracaena Species were authenticated at Bio-diversity Development and conservation, Nsukka, where the voucher specimens were deposited. 


\subsection{Morphological studies}

The vegetative studies on the two Dracaena species collected was done by visual observation and use of hand lens. Leaf morphology (leaf length and leaf width) stem morphology (internode length and stem colour), floral, fruit and seed morphology were also analyzed.

\subsection{Palynological studies}

Pollen extraction and concentration

Polleniferous materials were extracted from the flowers of $D$ mannii and D. arborea with the aid of a forcep and alcohol. Each sample was sieved through $200 \mathrm{u}$-mesh copper wire guaze to filter off other large floral particles. The samples were then centrifuged at 2000 revolutions per minute $(\mathrm{rpm})$ for three minutes. The supernatant was decanted and residue retained. The residue (ppt.) was washed three times with water and centrifuged in order to recover the polleniferous residue.

\subsection{Acetolysis}

This is a process employed in the preparation of the palynomorphs for microscopic analysis. The acetolysing agent is a mixture of concentrated tetraoxosulphate (VI) acid and acetic anhydride (1: 9) (Erdtman, 1934). The steps involved in the treatment of the residue are as follows:

$2-3 \mathrm{ml}$ of the acetolysis mixture was added into each of the residues. This was followed by heating in a water bath for five minutes at $100^{\circ} \mathrm{C}$. The samples were each washed with glacial acetic acid and three times with distilled water. Each wash was followed by centrifugation and decanting in order to recover the polleniferfous residue. The acetolysed samples were each transferred into specimen (vial) tubes and $5 \mathrm{ml}$ glycerol/alcohol was added and stored for analysis.

\subsection{Microscopic analysis of temporary slide}

$2 \mathrm{ml}$ of each sample were placed on a microscopic slide and covered carefully with a $22 \mathrm{~mm}$ x $22 \mathrm{~mm}$ cover slip. The mount was then sealed off around the edges with nail varnish to avoid dessication and movement of the cover slip. The slides were each examined microscopically and the palynomorphs identified with the use of "Leica Gallen" 11 1500008KX Microscope at x 400 magnification. The x100 magnification (oil immersion) was used for the detailed morphological study of pollen grains. Measurements were taken with the aid of ocular micrometer and photomicrographs were made.

\subsection{Statistical procedure}

The results were analyzed using t-test and results were presented in mean $\pm \mathrm{SD}$.

\section{Results}

The results of the study were presented below.

\subsection{The external morphology of Dracaena arborea}

The study showed that the external morphology of Dracaena is as follows:
Leaf simple, alternate, pentastichous; leaf shape lanceolate; leaf margin entire; leaf apex acute; leaf base attenuate; leaf mid rib conspicuous on the adaxial and abaxial surfaces and milky green in colour; leaf with sheathing at the base; leaf colour dark green; leaf length ranges from $32 \mathrm{~cm}-156 \mathrm{~cm}$; leaf breadth (broadest portion) ranges from $7.5 \mathrm{~cm}-12.4 \mathrm{~cm}$; venation parallel. The distance between the leaf internodes ranges from $2.4 \mathrm{~cm}-4.6 \mathrm{~cm}$. Stem woody, smooth with white patches; prop root present on the branches of older trees; internodes distinct in young stem; habit tree. Inflorescence: flower aggregated in panicle; flowers minute, regular, 3 merous, cyclic; perianth of tepals 6 and joined, 2 whorled, isomerous, petaloid (similar in the two whorls); plant hermophroditee; androcium 6; androecial members adnate (at the bases of the tepal lobes), all equal, free from one another, 1 whorled; stamens 6, dipostemonous; anthers dorsifixed; gynoecium 3 carpelled; carpels isomerous with the perianth; gynoecium superior; ovary 3 locular; gynoecium stylate; style 1, apical; stigmas 1, trilobite; placentation axile; ovules 1 per locule; fruit fleshy, indehiscent, a drupe(orange); seeds endospermic; cotyledon 1 ; embryo straight.

\subsection{The external morphology of Dracaena mannii}

From the study conducted, the external morphology of D. mannii is as follows: Leave simple, alternate, sessile, exstipulate; phyllotaxy pentastichous or 5- ranked; leaf colour dark green; leaf with sheathing at the base; leaf apex acute; leaf margin entire; leaf base attenuate; leaf shape lanceolate; leaf mid rib not conspicuous on the adaxial surface but conspicuous on the abaxial surface and milky green in colour; leaf length, width and internode distance range from $29.9 \mathrm{~cm}-56.1 \mathrm{~cm}, 2.5 \mathrm{~cm}-4.2 \mathrm{~cm}$ and $1.0 \mathrm{~cm}-1.8 \mathrm{~cm}$ respectively. Stem woody, deeply fissured longitudinally; young stem often with short internodes. Inflorescence: flower aggregated in panicles, flowers minute, regular, 3 merous, cyclic; perianth of tepals 6 and joined, 2 whorled, isomerous, petaloid (similar in the two whorls); plant hermaphrodite; androecium 6; androecial members adnate (at the bases of the tepal lobes), all equal, free from one another, 1 whorled; stamens 6 , dipostemonous; anthers dorsifixed; gynoecium 3 carpelled; carpels isomerous with the perianth; gynoecium superior; ovary 3 locular; gynoecium stylate; styles 1, apical; stigmas 1, trilobite; placentation axile; ovules 1 per locule; fruit fleshy, indehiscent, a drupe(orange); seeds endospermic; cotyledon 1; embryo straight.

\subsection{Pollen morphology}

The analysis of the pollen grains of $D$. mannii and $D$. arborea revealed the length of the polar axis to range from $87 \pm 0.82$ to $92 \pm 0.76$ and $78 \pm 0.85$ to $83 \pm 0.73$ respectively. Length of equatorial axis $64 \pm 0.41$ to $67 \pm 0.54$ and $48 \pm 0.57$ to $52 \pm 0.68$ respectively. Length of colpus $78 \pm 1.42$ to $86 \pm 1.11$ and $75 \pm 0.82$ to $79 \pm 0.44$ respectively. Diameter of colpus $6 \pm 0.32$ to $8 \pm 0.32$ and $4 \pm 0.44$ to $6 \pm 0.19$ respectively. Pollen form index $1.3 \pm 0.02$ to $1.4 \pm 0.01$ and $1.6 \pm 0.01$ to $1.7 \pm 0.03$ respectively. Exine thickness $2 \pm 0.19$ to $3 \pm 0.13$ and $2 \pm 0.22$ to $3 \pm 0.09$ respectively. The pollen grains in both species are monocolpate (possessing single colpus each). The surface of their pollen grains are scabrate to psilate (the surface of the pollen grains are rough). Their pollen grains are prolate in shape (fig.1 e and f): 
(a)

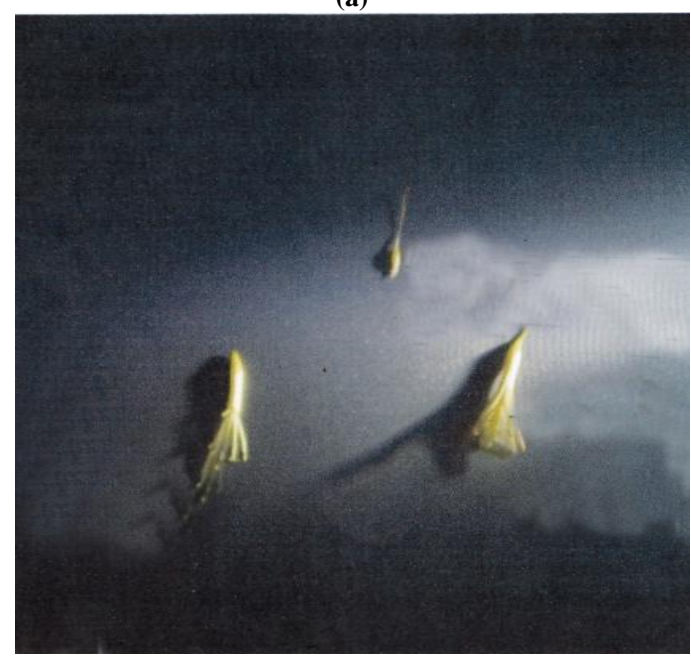

(c)
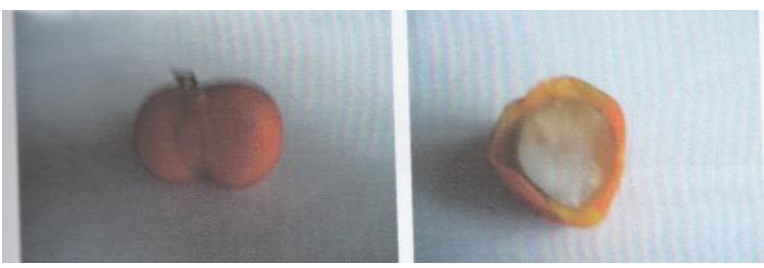

(e)

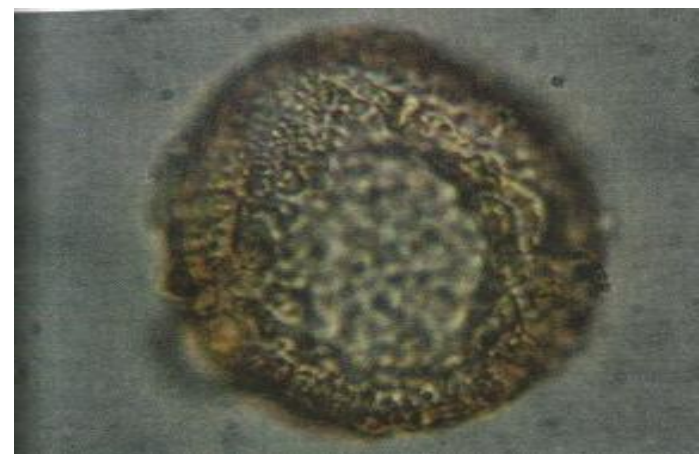

(b)

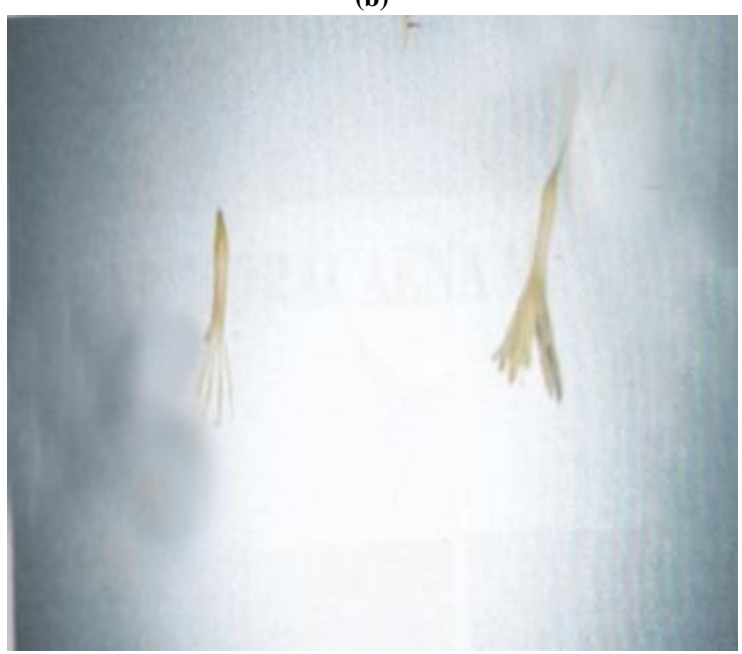

(d)

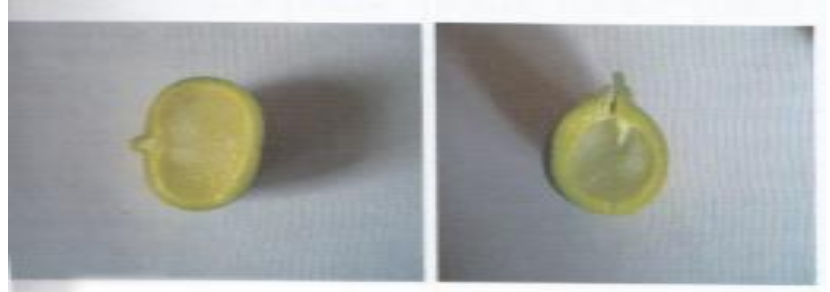

(f)

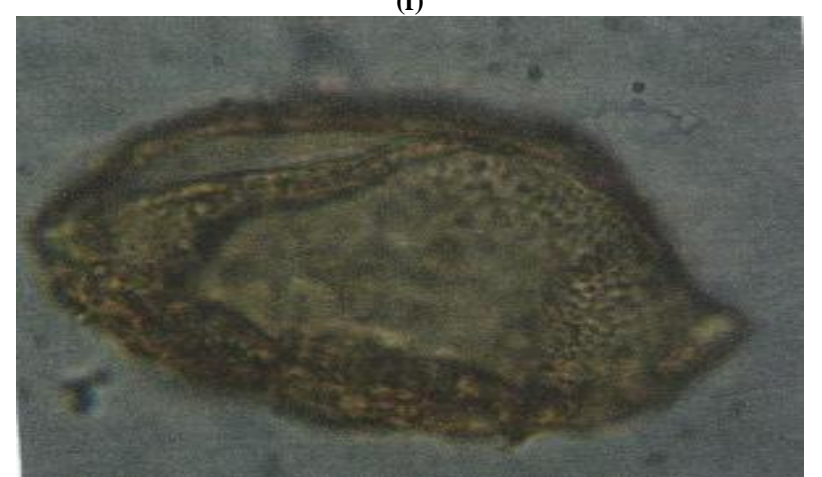

Fig. 1: (A-F): Showing Flowers, Fruits and Pollen of Draceana Species (A) D. arborea Flower, (B) D. mannii Flower, (C) D. mannii Fruit, (D) D. arborea Fruit, (E) D. manni Pollen and (F) D. arborea Pollen.
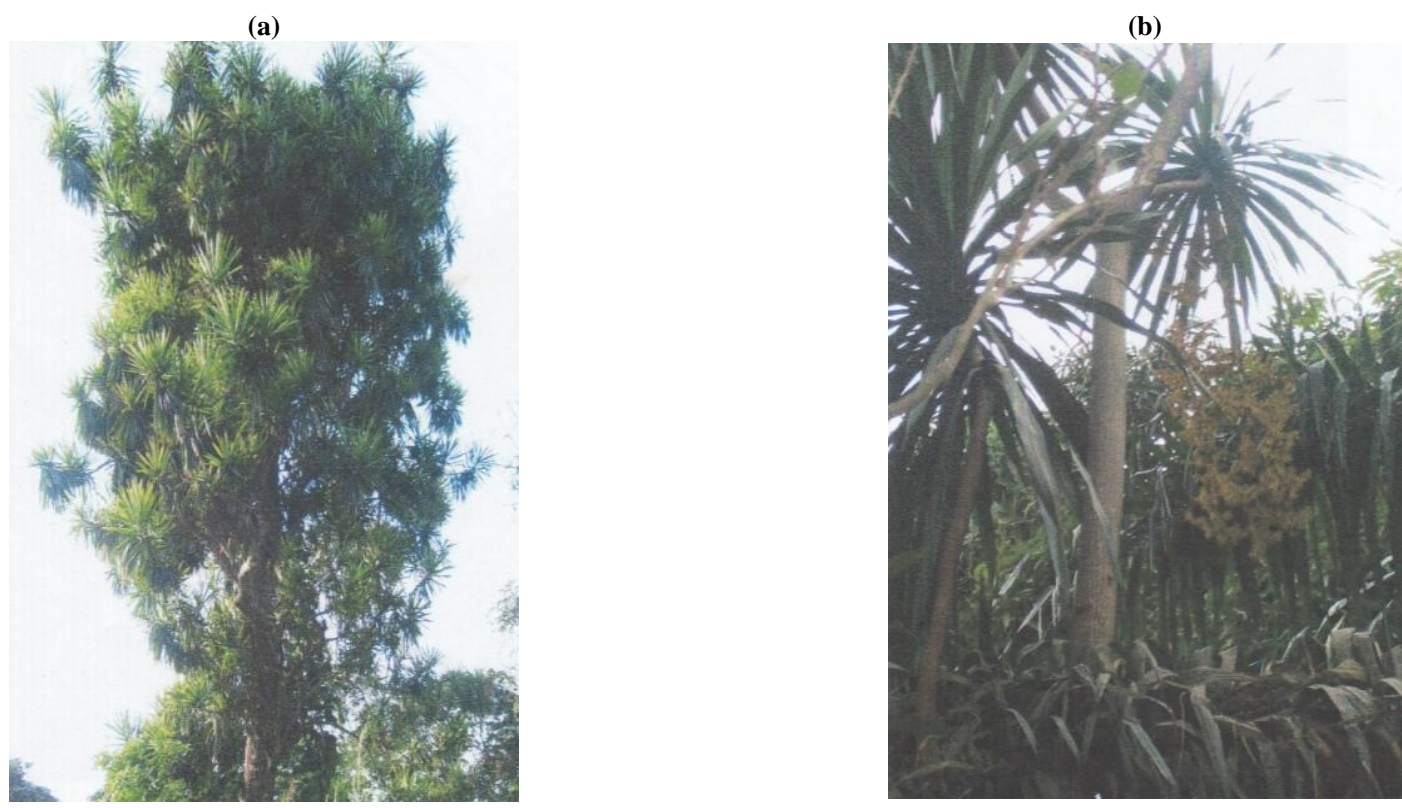

Fig. 2: (A-B): (A) D. mannii and (B) D. arborea 


\section{Discussion}

From the research carried out, there is significant difference in the external morphology of Dracaena arborea and Dracaena mannii. Both species are trees, however, D. arborea has smooth bark with white patches, with branches of older trees having prop roots while $D$. mannii tree bark is deeply fissured longitudinally and lacks prop roots(fig. $2 \mathrm{a}$ and b respectively). Significant statistical difference exists between the lengths and widths of the leaves as well as the distance between the nodes of the two species at $\mathrm{P}=$ 0.05 . D. arborea had the longest leaf of $156 \mathrm{~cm} \pm 13.57$ in length, broadest leaf of $12 \mathrm{~cm} \pm 5.35$ and an internode length of $4.60 \mathrm{~cm} \pm 2.19$. The inflorescence, flower, fruit and seed morphology of both plants are the same as shown by the result of the study. With the exception of the fruits of both species being drupes, the result of the inflorescence, flower, fruit and seed morphology of both species tally with an earlier study by Watson and Dallwitz (1992) in which they outlined the external morphology of Dracaenas as follows: Habit and leaf form: shrubs, or arborescent; leaves small to very large, alternate, spiral, herbac eous or leathery or fleshy, with free margins. Leaves simple; lamina entire, linear or lanceolate; parallel-veined, without cross venules, internode present (short). Inflorescence, floral, fruit and seed morphology: flower aggregated in inflorescences, in racemes, in umbels or in panicles. The terminal inflorescence unit is racemose. Flower s minute to large, regular, 3 merous, cyclic or pentacyclic; perianth of tepals 6 and joined, 2 whorled, isomerous petaloid (similar in the two whorls); unisexual flowers absent; plant hermaphrodite; androecium 6; androecial members adnate (at the bases of the tepal lobes), all equal, free from one another, 1 whorled or 2 whorled; androecium exclusively of fertile stamens; stamens 6, dipostemonous, anthers dorsifixed, dehiscing via longitudinal slit; gynoecium 3 carpelled; carpels isomerous with the perianth; the pistol 3 celled; gynoecium syucarpous, superior; ovary 3 locular; gynoecium stylate; styles 1 , apical; stigmas 1, trilobite or capitates; placentation axile; ovules 1 per locule; fruit usually fleshy or non-fleshy, indehiscent, usually a berry(typically red or orange), or a capsule or capsular-indehiscent(usually woody); seeds endospermic; endosperm oily; cotyledon 1; embryo straight.

The result of the pollen analysis of the two species showed that there was no significant difference in the: sizes of the pollen grains of species, their pollen form indices as well as the length and diameter of their colpi. Both of them are monocolpate. The surfaces of their pollen grains are scabrate. Sizes of their colpi differ in length and diameter. The colpus in $D$. mannii is longer than that of D. arborea.

\section{Conclusion}

The overall result of the study showed that there is no significant difference in the morphology and palynology of D. mannii and $D$. arborea. In other words, the two species are closely related and this justifies their placement in the same genus Dracaena. The slight differences existing between them also justify their separation into different species.

\section{References}

[1] Dutta AC (2003) Botany for Degree Students, (6 ed), Oxford University Press, India, pp. 301-588.

[2] Gill LS (1988) Taxonomy of Flowering Plants, African-Feb Publishers Limited, Onitsha, Nigeria, pp 23-35.

[3] Huxley A (1992) New RHS Dictionary of Gardening 2:96-97.

[4] Judd WS, Campbell CS, Kellogg, EA, \& Stevens PE (1999) Plant Systematics: A Phylogenetic approach Sinauer Associates, Inc. Sunderland, Massachusetts U.S.A, pp. 208-305.

[5] Philipson WR (1971) Ovular morphology and major classification of dicotyledons, Botanical Journal of Linnaen Society, 68:89-108. http://dx.doi.org/10.1111/j.1095-8339.1974.tb01750.x.
[6] Radford AE (1986) Fundamentals of Plant Systematics, Harper and Row, New York, pp. 302-322.

[7] Sharma OP (1993) Plant Taxonomy, Tatam McGraw-Hill Publishing Company Limited, /New Delhi, pp. 68-181.

[8] Venter F and Venter J (1995) Making the most indigenous trees. Farmers Weekly, 24 March: 66-67.

[9] Waston L \& Dallwitz MJ (1992) The families of flowering plants: Interactive identifications and information retrieval 4: 212-234.

[10] Waterhouse JT (1987) The Phylogenetic of Draceana-type growth. Proc. Linn. Soc. N.S.W. 109: 129-128. 